\title{
Original
}

\section{The Long-Term Effect of Replacement Therapy in a Short Girl with Autoimmune Atrophic Thyroiditis of Prepubertal Onset}

\author{
Jiro Kagawa, Isao Asakura, Nobuyasu Shimizu, \\ Kenichi Hibino, Mitsuhiro Ito and Takeshi Ikegaya \\ Department of Pediatrics, Fujieda Municipal Hospital, Fujieda, Japan
}

\begin{abstract}
A 9 yr 11 mo old girl was admitted to our hospital because of short stature. Her growth rate gradually decreased and her height was $120 \mathrm{~cm}(-2.5 \mathrm{SD})$ on admission. The mother's and father's heights were $157 \mathrm{~cm}(-0.2 \mathrm{SD})$ and $163 \mathrm{~cm}(-1.3 \mathrm{SD})$, respectively. Her bone age was retarded (6 yr $10 \mathrm{mo})$. An MRI indicated pituitary enlargement, which mimicked adenoma. Evaluation of the pituitary-thyroid axis and thyroid function proved she had primary hypothyroidism ( $\mathrm{T}_{3} 0.5 \mathrm{ng} / \mathrm{ml}, \mathrm{T}_{4} 1.0 \mu \mathrm{g} / \mathrm{dl}, \mathrm{TSH} 1,030 \mu \mathrm{U} /$ $\mathrm{ml}$ ). These findings, thyroid autoantibody (anti-microsome antibody $400 \mathrm{xs}$ ) and histopathology (moderate fibrosis and mild lymphocytic infiltration) suggested acquired hypothyroidism due to autoimmune atrophic thyroiditis of prepubertal onset. Since the evaluation, she has been treated with levothyroxine. The pituitary enlargement disappeared within 3 mo after levothyroxine replacement. The growth rate increased and her height reached $153.2 \mathrm{~cm}(-1.0 \mathrm{SD})$ during $10 \mathrm{yr}$ replacement (at $19 \mathrm{yr} 11 \mathrm{mo}$ of age). An improvement in her final height was obtained by long-term thyroid hormone replacement therapy. Enough endocrinological study and repeated MRI evaluation are necessary in cases of pituitary enlargement which mimics adenoma before considering surgery.
\end{abstract}

Key words: autoimmune thyroiditis, primary hypothyroidism, short stature, pituitary enlargement, replacement therapy

\section{Introduction}

Juvenile primary hypothyroidism may result in a permanent height deficit (1). Autoimmune atrophic thyroiditis is an uncommon disease in childhood. Patients with this disorder of prepubertal onset develop juvenile acquired primary hypothyroidism which is a cause of short stature $(2,3)$.

Received: September 4, 2003

Accepted: March 5, 2004

Correspondence: Dr. Jiro Kagawa, Department of Pediatrics, Fujieda Municipal Hospital, 4-1-11 Surugadai, Fujieda city, Shizuoka 426-8677, Japan
We report a short girl with pituitary enlargement, which mimicked macroadenoma (pseudoadenoma) due to autoimmune atrophic thyroiditis. And we also report the long-term effect of levothyroxine replacement therapy on her final height.

\section{Patient Report}

A 9 yr 11 mo old girl was admitted to our hospital because of short stature and suspicion of pituitary tumor. She was a product of $41 \mathrm{wk}$ gestational age and her birth weight was $3930 \mathrm{~g}$. She had been healthy, and her growth and 


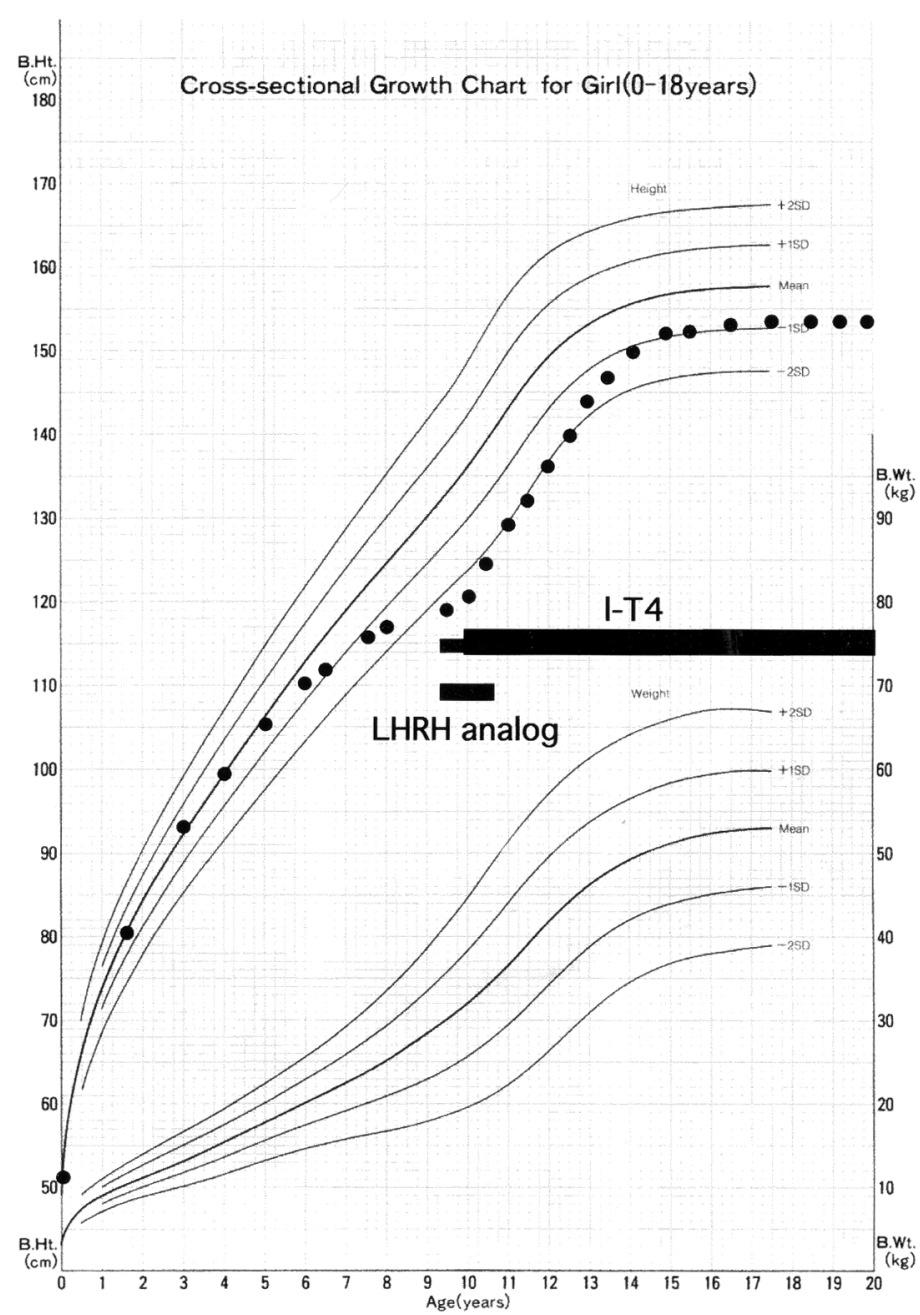

Fig. 1 Changes in height plotted on the female standard growth curves for Japanese.

development were normal until she reached 5 yr of age. Her family history was unremarkable. Her growth rate gradually decreased after 5 yr of age and her height was $120 \mathrm{~cm}(-2.5 \mathrm{SD})$ and body weight was $29 \mathrm{~kg}$ (degree of obesity: $+32.6 \%$ ) on admission (Fig. 1). She was a short and obese girl without goiter or webbed neck, and was in early puberty (breast development of Tanner stage II). The mother's and father's heights were $157 \mathrm{~cm}$ $(-0.2 \mathrm{SD})$ and $163 \mathrm{~cm}(-1.3 \mathrm{SD})$, respectively. The target height for her family was $153.5 \mathrm{~cm}$. Her bone age was retarded (6 yr 10 mo). Enlargement of the sella turcica in a plain cranial X-ray and MRI findings indicated pituitary enlargement, which mimicked macroadenoma (Fig. 2). The evaluation of the pituitary-thyroid axis (serum basal and TRH stimulated peak TSH levels were $1,030 \mu \mathrm{U} / \mathrm{ml}$ and $2,420 \mu \mathrm{U} / \mathrm{ml}$, respectively) and thyroid function $\left(\mathrm{T}_{3} 0.5 \mathrm{ng} / \mathrm{ml}, \mathrm{T}_{4} 1.0 \mu \mathrm{g} / \mathrm{dl}\right.$ ) proved she had severe primary hypothyroidism. Ultrasonography of the neck proved that the thyroid gland was not enlarged but relatively small in spite of significant TSH increase. These findings, low basal metabolic rate $(-22.3 \%)$, positive thyroid autoantibody (anti- 


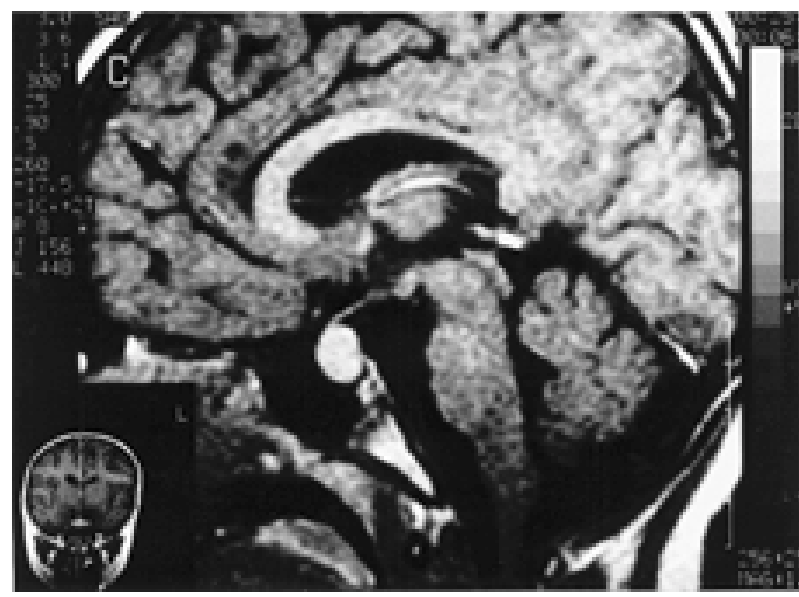

Fig. 2 Pituitary mass with suprasellar expansion was proven by MRI. Gadolinium-enhanced image.

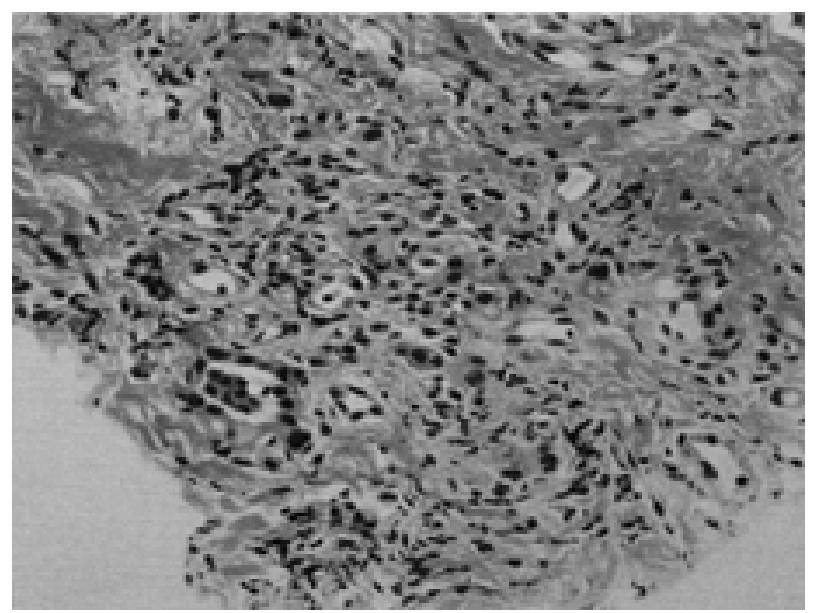

Fig. 3 Histopathology of thyroid tissue (needle biopsy). Moderate fibrosis and mild lymphocytic infiltration. Magnification, $\times 80$.

microsome antibody $400 \mathrm{xs}$ ) and the histopathology of thyroid tissue obtained by needle biopsy (Fig. 3: moderate fibrosis and mild lymphocytic infiltration) suggested juvenile acquired primary hypothyroidism due to autoimmune atrophic thyroiditis of prepubertal onset. The increase in the pituitary-gonadal axis also proved pubertal response (serum LH and FSH levels after LHRH stimulation were $29.4 \mathrm{mIU} / \mathrm{ml}$

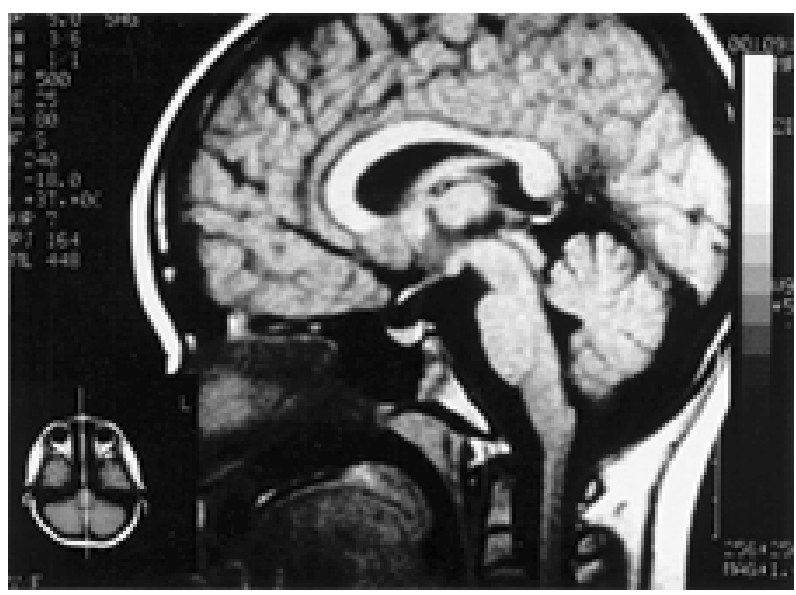

Fig. 4 The pituitary enlargement disappeared on serial MRI after three months of thyroid hormone replacement.

and $16.6 \mathrm{mIU} / \mathrm{ml}$, respectively).

Since the evaluation, she has been treated with levothyroxine. The dose of levothyroxine was gradually increased to $100 \mu \mathrm{g} /$ day, and this medication was continued thereafter. The serum thyroxine concentrations were maintained in the normal range during levothyroxine replacement. The pituitary enlargement disappeared on serial MRI after three months of thyroid hormone replacement (Fig. 4). Thyroid autoantibodies have been positive (anti-microsome antibody 6400$102400 \mathrm{xs}$, anti-thyroglobulin antibody 100-400 xs) during levothyroxine replacement.

Intranasal LHRH analog (buserelin) was administered for two years (from 10 yr 0 mo to 11 yr 11 mo of age) to suppress the pubertal development, because severe juvenile hypothyroidism could cause a distinct form of isosexual precocity (4). Her pubertal development was suppressed during LHRH analog treatment. The growth rate and the maturation of bone increased after levothyroxine and LHRH analog administration, and her bone age reached 10 yr 6 mo at the end of LHRH analog therapy (11 yr 11 mo of chronological age). The onset of menarche occurred at 14 yr 2 mo of age, and she had regular 
menstrual cycles thereafter. At 15 yr 7 mo of age her height and bone age reached $152.8 \mathrm{~cm}$ and 15 yr 0 mo, respectively. Her height at $19 \mathrm{yr} 11 \mathrm{mo}$ of age reached $153.2 \mathrm{~cm}(-1.0 \mathrm{SD})$ after ten years of levothyroxine replacement (Fig. 1).

\section{Discussion}

We reported a short girl with autoimmune atrophic thyroiditis of prepubertal onset. Her height SD score was $-2.5 \mathrm{SD}$ at the start of levothyroxine therapy. Her final height reached $153.2 \mathrm{~cm}(-1.0 \mathrm{SD})$ after ten years of levothyroxine replacement. It was comparable with her target height $(153.5 \mathrm{~cm})$ and $1.0 \mathrm{SD}$ shorter than projected height from the height before onset of hypothyroidism (at 5 yr of age). Serious loss of the final height was prevented by long-term thyroid hormone replacement therapy. A permanent deficit in adult height has been reported in patients with autoimmune thyroiditis with long-standing hypothyroidism despite adequate treatment with levothyroxine (1). Early recognition and treatment of the disease should be achieved for a preventive care of hypothyroidism before serious short stature $(-3$ or $-4 \mathrm{SD})$ results. The effect of two year LHRH analog therapy on her final height improvement was not sufficient. Her pubertal development was suppressed during LHRH analog treatment, but maturation of bone was not sufficiently suppressed by LHRH analog therapy. Her bone age was 6 yr 10 mo on admission and reached 10 yr 6 mo at the end of two years LHRH analog therapy.

Pituitary enlargement (thyrotroph hyperplasia) as a result of primary hypothyroidism is a well-recognized entity (5). Thyroid hormone therapy causes a regression of pituitary thyrotoroph hyperplasia (6). After levothyroxine replacement therapy, the pituitary enlargement in our patient resolved within a few months, but sometimes it may be difficult to distinguish between hyperplasia and adenoma, and pituitary enlargement may also have been secondary to thyroid failure. Before considering surgical procedures for patients with pituitary enlargement which mimics adenoma, a continuous effort to perform enough endocrinological studies, which include a trial of replacement therapy for thyroid hormone deficiency and repeated MRI evaluations, are suggested to exclude hypothyroid induced pituitary swelling.

\section{Acknowledgments}

Part of this report was presented in the 106th Annual Meeting of the Japan Pediatric Society (Fukuoka).

\section{References}

1. Rivkees SA, Bode HH, Crawford JD. Long-term growth in juvenile acquired hypothyroidism: the failure to achieve normal adult stature. N Engl J Med 1988;318:599-602.

2. Niedziela M, Korman E. Severe hypothyroidism due to autoimmune atrophic thyroiditispredicted target height and a plausible mechanism for sexual precocity. J Pediatr Endocrinol Metab 2001;14:901-7.

3. Pantsiouou S, Stanhope R, Uruena M, Preece MA, Grant DB. Growth prognosis and growth after menarche in primary hypothyroidism. Arch Dis Child 1991;66:838-40.

4. Fisher D. The thyroid. In: Kaplan S, editor. Clinical pediatric endocrinology. 2nd ed. Philadelphia: Saunders; 1990. p. 87-126.

5. Kawahara K, Tsukimoto I, Yokoya S. Atrophic autoimmune thyroiditis with positive thyroid stimulation blocking antibody in a prepubertal boy. Clin Pediatr Endocrinol 2000;9:105-11.

6. Kuroiwa T, Okabe Y, Hasuo K, Yasumori K, Mizushima A, Masuda K. MR imaging of pituitary hypertrophy due to juvenile primary hypothyroidism: a case report. Clin Imaging 1991;15:202-5. 